\title{
Childhood sexual abuse and risks for licit and illicit drug-related outcomes: a twin study
}

\author{
ELLIOT C. NELSON ${ }^{1 *}$, ANDREW C. HEATH ${ }^{1}$, MICHAEL T. LYNSKEY ${ }^{1}$, \\ KATHLEEN K. BUCHOLZ ${ }^{1}$, PAMELA A. F. MADDEN ${ }^{1}$, DIXIE J. STATHAM ${ }^{2}$ \\ AND NICHOLAS G. MARTIN ${ }^{2}$ \\ ${ }^{1}$ Washington University School of Medicine, Department of Psychiatry, St Louis, MO, \\ USA $;{ }^{2}$ Queensland Institute of Medical Research, Brisbane, Australia
}

\begin{abstract}
Background. This study examined the relationships between self-reported childhood sexual abuse (CSA) and drug-related outcomes in an Australian twin panel.

Method. A semi-structured psychiatric interview was conducted in 1996-2000 by telephone with young adult Australian twins (mean age 29.9 years). Data reported here are from 6050 twins who responded to both CSA and drug-related items.

Results. A history of CSA was associated with significant risk for subsequently occurring regular smoking and use of each illicit drug class. Further CSA-associated risk was found among regular users, for nicotine and alcohol dependence, and among illicit drug users, for abuse/dependence of most drug classes. In same-sex discordant pairs, significant risk for regular smoking and illicit drug use was found in twins with a history of CSA compared to their non-abused co-twins. Similar analyses for abuse/dependence found significant risk for opioids, any illicit drug, and any noncannabis illicit drug. CSA was associated with significantly earlier drug use. Despite the association of CSA with risk for early-onset cannabis use and regular smoking, risks for illicit drug outcomes associated with CSA and with either form of early-onset use combine in near-additive fashion.
\end{abstract}

Conclusions. CSA is associated with risk for subsequently occurring regular smoking and illicit drug use and abuse/dependence. Risks for drug use are mildly attenuated with control for familial contributions; similar risks for abuse/dependence remain significant for opioids and for illicit drugs combined across classes. Although we found evidence of earlier onset drug use with CSA, risks associated with CSA and with early-onset use combine in a largely additive manner.

\section{INTRODUCTION}

A high prevalence of childhood abuse has been reported in samples of adolescents (Harrison et al. 1989; Clark et al. 1997) and adults (Bartholomew et al. 2002; Simpson \& Miller, 2002) receiving substance use disorders (SUDs) treatment. Although maltreatment occurs in various forms, childhood sexual abuse (CSA) is the most studied (Simpson \& Miller, 2002). In

* Address for correspondence: Elliot C. Nelson, M.D., Washington University School of Medicine, Department of Psychiatry, 660 South Euclid Avenue, St Louis, MO 63110, USA.

(Email: nelsone@wustl.edu) adolescents receiving SUDs treatment, a history of CSA was associated with earlier initiation of licit and illicit drug use (Harrison et al. 1989). Similarly, earlier injection drug use occurs in adult injection drug users with a history of CSA (Ompad et al. 2005).

Ethically and legally mandated reporting has caused investigators to reject prospective, naturalistic examinations for other research designs. Anonymous, questionnaire-based assessment of large, school-ascertained samples (Harrison et al. 1997; Bensley et al. 1999) have found CSA-associated risk for licit and illicit substance use including earlier initiation and greater 
frequency of use. Given that Lynskey et al. (2003) found early-onset cannabis use (i.e. prior to age 17) to be a significant risk factor for use and abuse/dependence of other illicit drugs in their sample, CSA-associated earlier onset substance use could also be a source of risk for these more distal outcomes.

Examinations in general population samples that have obtained CSA history by retrospective report from young adults have confirmed associations with substance dependence (Mullen et al. 1993; Fergusson et al. 1996 b; Molnar et al. 2001). However, reports have also noted that parental SUDs are associated with significant risk for offspring CSA (Fergusson et al. 1996b; Fleming et al. 1997; Nelson et al. 2002; Walsh et al. 2003). As SUDs are known to be moderately heritable (Heath et al. 1997; Tsuang \& Lyons, 1998; Kendler et al. 2003), it is possible that parental SUDs may be a source of risk in offspring for both CSA and drug-related outcomes. Unfortunately, investigations in general population samples have included limited assessment of, and control for, parental psychopathology.

Twin studies (Kendler et al. 2000; Nelson et al. 2002) enable additional methods of controlling for familial background while estimating adversity-associated risk. Because twins share family background risk factors, co-twin control comparisons made in CSA-discordant pairs provide a useful means of estimating CSA-associated risk. Optimally, comparisons limited to monozygotic (MZ) twins would enable complete control for genetic and family environmental risk factors. However, because only data from pairs discordant for both CSA and the examined outcome are informative for these analyses, sample size limitations generally necessitate including discordant dizygotic (DZ) pairs (Kendler et al. 2000; Nelson et al. 2002).

Kendler et al. (2000) assessed CSA history by a mailed questionnaire and substance dependence by an in-person interview in adult female twins. They found CSA-associated risks for alcohol and any illicit drug dependence that remained significant, with inclusion of family functioning measures as covariates. The risks were greatest when CSA involved intercourse. They examined risks in CSA-discordant pairs in analyses that incorporated varying degrees of
CSA and discordance. All odd ratios were greater than unity for alcohol dependence (half reached significance). For drug dependence, most risks fell below significance, presumably limited by the small numbers (5-15) of doublydiscordant pairs.

The current report examines the relationship between CSA and licit and illicit drug outcomes in a large Australian young adult twin cohort. We extend findings from previous reports by: (1) providing separate estimates of risk for two classes of licit drugs and five classes of illicit drugs; (2) excluding individuals whose use of the specific drug being examined predated their first occurrence of CSA; (3) separately estimating CSA-associated risks for $(a)$ drug use and $(b)$ drug-related disorders among users; (4) using a large sample of CSA-discordant twins to estimate CSA-associated risks controlling for family background factors; and (5) estimating the risks associated with CSA only, early-onset substance use only, and both in combination, and examining whether a significant interaction is seen that would have important implications for prevention efforts.

\section{METHOD}

\section{Sample}

The young adult cohort of the Australian Twin Register is a volunteer panel composed of twins born 1964-1971 (Heath et al. 2001; Nelson et al. 2002; Lynskey et al. 2002, 2003; Knopik et al. 2004). Nearly all were registered by parents between 1980 and 1982 in response to approaches through school systems or mass media. Twins were recontacted and verbal consent obtained according to the protocol approved by the institutional review boards of Washington University School of Medicine and the Queensland Institute of Medical Research. Data reported here were collected between 1996 and 2000 by a comprehensive telephone assessment administered to all consenting cohort members by trained lay interviewers.

Of 4010 pairs that could be traced, interviews were completed with both members of 2765 pairs (69\% pairwise response rate) and one member of 735 pairs $(78 \%$ individual response rate). The current sample includes all 6050 individuals with data available for both CSA and drug use. The sample is $55.5 \%$ female; 
mean age is 29.9 years (s.D. $=2 \cdot 5$ ). The educational background of the sample suggests no major social class bias: $45 \cdot 6 \%$ did not graduate from high school, $20 \cdot 3 \%$ had a high school diploma without post-secondary education, and $34 \cdot 1 \%$ had some post-secondary education. The prevalence and characteristics of CSA in this cohort have been observed (Nelson et al. 2002) to resemble general population reports (Fergusson et al. 1996b; Fleming, 1997; Holmes \& Slap, 1998). The rates of illicit drug use are similar to those reported in an Australian epidemiological study (Australian Institute of Health and Welfare, 1999).

\section{Assessment of illicit drug-related outcome measures}

A standardized psychiatric diagnostic assessment adapted from the Semi-Structured Assessment for the Genetics of Alcoholism (SSAGA; Bucholz et al. 1994) was administered by telephone. The interview enabled lifetime DSM-IV (APA, 1994) diagnoses including nicotine (cigarettes only) dependence and alcohol dependence. Regular use of nicotine (at least weekly for 3 consecutive weeks) and alcohol (at least monthly for 6 consecutive months) was also queried.

The interview's illicit drug section assessed two of four abuse criteria and four of seven dependence criteria. Drug use disorders were operationalized according to Lynskey et al. (2002, 2003) (i.e. abuse as endorsement of either abuse criterion; probable dependence as endorsement of two or more dependence criteria). The abuse assessment, though diagnostic, would miss cases with maladaptive use limited to non-assessed categories. The non-diagnostic dependence assessment has excellent sensitivity and specificity for DSM-IV drug dependence (Lynskey et al. 2002, 2003). We combined abuse and dependence within each drug class as in Lynskey et al. (2003). We examined use (i.e. any whatsoever) and abuse/dependence of five classes of illicit drugs: (1) cannabis; (2) opiates; (3) sedatives (including benzodiazepines and barbiturates); (4) stimulants; and (5) cocaine. For the discordant pair analyses, two composite variables were coded to reflect the use of any, and any non-cannabis, illicit drug. Composite variables were similarly coded for any, and any non-cannabis, illicit drug abuse/dependence.
Early-onset use was defined as occurring before age 17 years for cannabis (Lynskey et al. 2003) and before age 16 for regular smoking.

\section{Assessment of CSA}

A composite variable for CSA was derived from five component questions (Nelson et al. 2002): (1) Before age 18 , were you ever forced into sexual intercourse or any other form of sexual activity? (2) Before you were 16 years old, were there any sexual contacts between you and anyone other than a family member who was 5 or more years older than you were? By sexual contact I mean their touching your sexual parts, you touching their sexual parts, or sexual intercourse (coded positively where subjects responded to a follow-up question that contact was 'ever forced'). (3) Before you were 16 years old, were there any sexual contacts between you and any family members, like a parent or step-parent, grandparent, uncle, aunt, brother or sister, or cousin? By sexual contact I mean their touching your sexual parts, you touching their sexual parts, or sexual intercourse (coded positively where subjects responded to further questions that contact involved either an adult or the use of force by a child). The final two questions contain descriptions in parentheses that were not read aloud to protect confidentiality (they appeared in a booklet mailed to respondents). This section was skipped if respondents misplaced their booklets. (4) How about event no. 5 [You were raped (someone had sexual intercourse with you when you did not want to, by threatening you or using some degree of force)]? (Included within CSA when first occurred before age 18.) (5) Apart from event no. 5 did event no. 6 [You were sexually molested (someone touched or felt your genitals when you did not want them to)] ever happen to you? A binary CSA variable was coded positive with endorsement of any of these items. Data were excluded from individuals who reported an onset $\geqslant 18$ years for all endorsed CSA items or from those refused to respond to a CSA component question without endorsing another component item. Data from nine individuals missing CSA onset were excluded from analyses requiring onset information. Although age 17 is the highest upper limit commonly used for CSA onset, our sample's mean onset is similar to values observed in general population samples. 


\section{Data analysis}

We used SAS (SAS Institute, 2000) and the Stata Statistics and Data Analysis Package version 6.0 (Stata Corporation, 1999) for analyses. An $\alpha$-level of 0.05 was required for significance. The robust variance estimator option in STATA adjusted all $95 \%$ confidence intervals (CIs) for the statistical non-independence of observations from twin pairs.

We calculated the prevalence of drug use, by CSA history, in women and men. We calculated the prevalence, by CSA history, of licit drug dependence in regular users, and illicit drug abuse/dependence in (ever) users.

We performed survival analysis using Cox proportional hazard regression models to estimate the CSA-associated risk, controlling for gender, for regular licit drug use and use of each illicit drug class. These analyses treated CSA as a time-dependent covariate to calculate hazard ratios, estimating outcome risks associated with the prior experience of CSA. We similarly examined the risk with the prior experience of CSA, controlling for gender, for: (1) licit drug dependence, limited to regular users; and (2) illicit drug abuse/dependence, limited to users of that drug class, using the age at first use for each drug as a conservative estimate for abuse/ dependence onset (not obtained).

We performed discordant pair analyses using conditional logistic regression to estimate the risk in CSA-positive versus CSA-negative pair members to examine CSA-associated risks controlling for the contribution of familial factors. Data from DZ opposite-sex pairs were excluded to eliminate bias due to gender differences in substance use and CSA prevalence. The remaining same-sex CSA-discordant pairs $(n=$ 280) included $96 \mathrm{MZ}$ female, $111 \mathrm{DZ}$ female, $31 \mathrm{MZ}$ male and $42 \mathrm{DZ}$ male pairs. Only data from doubly-discordant pairs (i.e. discordant for both CSA and the outcome being examined) are informative for these analyses. Odds ratios (ORs) are easily calculated as the ratios of the number of pairs in which the twin with a history of CSA is also outcome-positive $\left(n_{21}\right)$ to pairs in which the twin reporting CSA is outcomenegative $\left(n_{12}\right)$. The outcomes examined included the regular use of licit drugs and the use and abuse/dependence of illicit drugs of the various classes, any illicit drug, and any non-cannabis illicit drug. We excluded pairs in which the CSA-positive twin reported first use of the illicit drug being examined predated CSA onset. We report $n_{21}$ and $n_{12}$ separately by zygosity with ORs and $95 \%$ CIs only for the combined group. We used an option in STATA to test whether the risk estimates differed by zygosity or gender and reported values separately when we found significant interactions.

To test for the contribution of CSA to the age at onset of drug use, we fit a series of linear regression models that controlled for gender for which all values are in units of age (years). The intercept is the mean onset for CSA-negative women, and regression coefficients represent the incremental changes associated with CSA and male gender. We excluded individuals whose first use of the examined drug predated CSA onset. We used logistic regression to examine the CSA-associated risk, controlling for gender, for early-onset cannabis use. We coded dummy variables to represent a history of both CSA and early-onset cannabis use, CSA without early-onset cannabis use, or early-onset cannabis use without CSA for use in logistic regression analyses examining the risk for use and abuse/dependence of the illicit drug classes, controlling for gender. Additional logistic regression analyses that included main effects for gender, CSA, and early-onset cannabis use and an interaction term (CSA $\times$ early-onset cannabis use) evaluated whether significant interactions were found. We repeated these analyses substituting early-onset regular smoking for early-onset cannabis use and including cannabis outcomes as dependent variables.

\section{RESULTS}

A history of CSA was reported by $17.4 \%$ of women and $6.0 \%$ of men (OR $3 \cdot 31,95 \%$ CI $2 \cdot 73-4 \cdot 00)$. CSA began early [mean age $10 \cdot 7$ years (s.D. $=4.09)]$ and was preceded uncommonly by regular licit drug use and rarely by illicit drug use (regular smoking preceded CSA in 69 of 477 individuals reporting both; the similar ratios for other substances are: regular alcohol use $30 / 643$; cannabis use $24 / 542$; opioid use $0 / 101$; sedative use $5 / 145$; stimulant use $3 / 245$; and cocaine use 0/92).

Women and men with a history CSA more commonly reported regular smoking and use of 
Table 1. Comparison of the prevalence (\%) of licit and illicit substance outcomes by gender and childhood sexual abuse (CSA) status

\begin{tabular}{|c|c|c|c|c|c|c|c|c|}
\hline & \multicolumn{2}{|c|}{ Women $(n=3357)$} & \multicolumn{2}{|c|}{$\operatorname{Men}(n=2693)$} & \multicolumn{2}{|c|}{ Women } & \multicolumn{2}{|c|}{ Men } \\
\hline & $\mathrm{CSA}+$ & $\mathrm{CSA}-$ & $\mathrm{CSA}+$ & $\mathrm{CSA}-$ & $\mathrm{CSA}+$ & $\mathrm{CSA}-$ & $\mathrm{CSA}+$ & $\mathrm{CSA}-$ \\
\hline Licit & \multicolumn{4}{|c|}{ Regular use } & \multicolumn{4}{|c|}{ Dependence (among regular users) } \\
\hline Nicotine & $63 \cdot 8$ & $47 \cdot 8$ & $68 \cdot 9$ & $52 \cdot 5$ & $66 \cdot 1$ & $53 \cdot 3$ & $77 \cdot 5$ & $59 \cdot 2$ \\
\hline Alcohol & $85 \cdot 9$ & $86 \cdot 3$ & $92 \cdot 6$ & $93 \cdot 0$ & $32 \cdot 7$ & $14 \cdot 9$ & $45 \cdot 0$ & $32 \cdot 1$ \\
\hline Illicit & \multicolumn{4}{|c|}{ Any use } & \multicolumn{4}{|c|}{ Abuse/dependence (among users) } \\
\hline Cannabis & $71 \cdot 7$ & $49 \cdot 0$ & $82 \cdot 0$ & $67 \cdot 8$ & $34 \cdot 9$ & $19 \cdot 4$ & $50 \cdot 0$ & $34 \cdot 8$ \\
\hline Opioids & $11 \cdot 5$ & $4 \cdot 2$ & $23 \cdot 0$ & $6 \cdot 8$ & $37 \cdot 3$ & $16 \cdot 2$ & $29 \cdot 7$ & $10 \cdot 5$ \\
\hline Sedatives & $18 \cdot 0$ & $6 \cdot 9$ & $27 \cdot 3$ & $7 \cdot 7$ & $14 \cdot 3$ & $6 \cdot 3$ & $27 \cdot 3$ & $7 \cdot 7$ \\
\hline Stimulants & $29 \cdot 2$ & $13 \cdot 8$ & $49 \cdot 1$ & $24 \cdot 0$ & $24 \cdot 1$ & $16 \cdot 9$ & $32 \cdot 9$ & $20 \cdot 4$ \\
\hline Cocaine & $9 \cdot 1$ & $3 \cdot 9$ & $25 \cdot 5$ & $7 \cdot 2$ & $11 \cdot 3$ & $7 \cdot 3$ & $12 \cdot 2$ & $10 \cdot 4$ \\
\hline
\end{tabular}

Table 2. Hazard ratios (and 95\% confidence intervals, in parentheses) reflecting the risk for licit and illicit substance outcomes associated with the prior experience of childhood sexual abuse $(C S A)$, controlling for male gender $(n=6050)$

\begin{tabular}{|c|c|c|c|c|}
\hline & CSA & Male & CSA & Male \\
\hline Licit & \multicolumn{2}{|c|}{ Regular use } & \multicolumn{2}{|c|}{ Dependence (among regular users) } \\
\hline Nicotine & $1.49(1.32-1.67)$ & $1 \cdot 13(1 \cdot 05-1 \cdot 23)$ & $1.49(1.31-1.69)$ & $1 \cdot 22(1 \cdot 11-1 \cdot 34)$ \\
\hline Alcohol & $1 \cdot 06(0 \cdot 97-1 \cdot 15)$ & $1 \cdot 38(1 \cdot 31-1 \cdot 45)$ & $1.99(1 \cdot 71-2 \cdot 33)$ & $2 \cdot 19(1 \cdot 95-2 \cdot 46)$ \\
\hline Illicit & \multicolumn{2}{|c|}{ Any use } & \multicolumn{2}{|c|}{ Abuse/dependence (among users) } \\
\hline Cannabis & $1.73(1.57-1.92)$ & $1.62(1.51-1 \cdot 74)$ & $1 \cdot 73(1 \cdot 46-2 \cdot 05)$ & $1 \cdot 84(1 \cdot 61-2 \cdot 10)$ \\
\hline Opioids & $3.09(2 \cdot 43-3.95)$ & $1 \cdot 70(1 \cdot 37-2 \cdot 11)$ & $2 \cdot 60(1 \cdot 60-4 \cdot 22)$ & $0.65(0 \cdot 40-1 \cdot 06)$ \\
\hline Sedatives & $3.00(2 \cdot 44-3 \cdot 69)$ & $1 \cdot 21(1 \cdot 00-1 \cdot 46)$ & $2 \cdot 61(1 \cdot 43-4 \cdot 78)$ & $1 \cdot 46(0 \cdot 80-2 \cdot 64)$ \\
\hline Stimulants & $2 \cdot 28(1 \cdot 96-2 \cdot 66)$ & $1.82(1.61-2.06)$ & $1 \cdot 54(1 \cdot 13-2 \cdot 11)$ & $1.27(0.98-1.65)$ \\
\hline Cocaine & $2 \cdot 89(2 \cdot 25-3 \cdot 71)$ & $2 \cdot 08(1 \cdot 66-2 \cdot 60)$ & $1 \cdot 22(0 \cdot 58-2 \cdot 53)$ & $1 \cdot 27(0 \cdot 66-2 \cdot 44)$ \\
\hline
\end{tabular}

Values are in bold face where hazard ratio is significant $(p<0 \cdot 05)$.

each class of illicit drug examined, but not regular alcohol use (Table 1). Survival analysis revealed that, controlling for gender, a history of CSA is associated with significant risk for subsequently occurring regular smoking and use of all examined classes of illicit drugs (Table 2). The strongest effects were observed for opioids, sedatives and cocaine, the least prevalent drug classes. CSA is thus associated with significant risk for regular smoking and cannabis use, two fairly normative behaviours in our sample, but not with the almost ubiquitous regular alcohol use. Greater risk is observed for use of the lessprevalent illicit drugs.

Among regular users, a history of CSA was found by survival analysis to be associated with risk for nicotine and alcohol dependence. Similarly, among those reporting illicit drug use, a history of CSA was associated with significant risk for subsequently occurring abuse/ dependence of each examined class of drugs other than cocaine; the strongest effects were observed for opioids and sedatives. Among those who have initiated substance use, CSAassociated risk for substance use disorders is observed.

In CSA-discordant same-sex pairs, significant risk for regular smoking and use of cannabis, opioids, sedatives and cocaine was seen in twins reporting a history of CSA compared to their non-sexually abused co-twins; the risk for stimulant use fell just below significance (Table 3). Analyses that combined drug categories found significant risk in the twins with a history of CSA compared to their non-abused co-twins for any illicit drug use and any noncannabis illicit drug use. In similar examinations of drug abuse/dependence, risk estimates exceeded unity for all drug classes, but reached significance only for opioids (OR 6.50). Significant abuse/dependence risk was found for any illicit drug (OR 1.78) and any non-cannabis 
Table 3. Comparison of drug use and abuse/dependence in CSA+ versus CSA- members of same-sex discordant pairs $(n=280$ pairs $)$

\begin{tabular}{|c|c|c|c|c|}
\hline \multirow[b]{2}{*}{ Substance-related outcome } & \multicolumn{3}{|c|}{$n_{21} / n_{12}$} & \multirow{2}{*}{$\begin{array}{c}\text { Within-pair risk } \\
\text { OR }(95 \% \text { CI })\end{array}$} \\
\hline & $\mathrm{MZ}$ & $\mathrm{DZ}$ & Combined & \\
\hline \multicolumn{5}{|l|}{ Licit - regular use } \\
\hline Nicotine & $17 / 7$ & $28 / 19$ & $45 / 26$ & $1 \cdot 73(1 \cdot 07-2 \cdot 81)$ \\
\hline Alcohol & $7 / 8$ & $12 / 7$ & $19 / 15$ & $1 \cdot 27(0 \cdot 64-2 \cdot 49)$ \\
\hline \multicolumn{5}{|l|}{ Illicit - any use } \\
\hline Cannabis & $19 / 17$ & $29 / 12$ & $48 / 29$ & $1.66(1.04-2.62)$ \\
\hline Opioids & $6 / 8$ & $21 / 5$ & $27 / 13$ & $2 \cdot 08(1.07-4 \cdot 03)$ \\
\hline Sedatives & $15 / 9$ & $23 / 11$ & $38 / 20$ & $1.90(1 \cdot 11-3 \cdot 27)$ \\
\hline Stimulants & $18 / 9$ & $24 / 17$ & $42 / 26$ & $1.62(0.99-2.63)$ \\
\hline Cocaine & $9 / 4$ & $14 / 5$ & $23 / 9$ & $2 \cdot 56(1 \cdot 18-5 \cdot 52)$ \\
\hline Any illicit drug & $22 / 13$ & $29 / 14$ & $51 / 27$ & $1 \cdot 89(1 \cdot 19-3 \cdot 01)$ \\
\hline Non-cannabis illicit drug & $23 / 11$ & $36 / 22$ & $59 / 33$ & $1 \cdot 79(1 \cdot 17-2 \cdot 74)$ \\
\hline \multicolumn{5}{|l|}{ Illicit-abuse/dependence } \\
\hline Cannabis & $11 / 11$ & $21 / 14$ & $32 / 25$ & $1 \cdot 28(0 \cdot 76-2 \cdot 16)$ \\
\hline Opioids & $5 / 1$ & $8 / 1$ & $13 / 2$ & $6 \cdot 50(1 \cdot 47-28 \cdot 80)$ \\
\hline Sedatives & $3 / 0$ & $6 / 2$ & $9 / 2$ & $4.50(0 \cdot 97-20 \cdot 83)$ \\
\hline Stimulants & $7 / 3$ & $12 / 8$ & $19 / 11$ & $1.73(0.82-3.63)$ \\
\hline Cocaine & $2 / 1$ & $4 / 2$ & $6 / 3$ & $2 \cdot 00(0 \cdot 50-8 \cdot 00)$ \\
\hline Any illicit drug & $14 / 8$ & $27 / 15$ & $41 / 23$ & $1.78(1.07-2.97)$ \\
\hline Non-cannabis illicit drug & $8 / 3$ & $16 / 8$ & $24 / 11$ & $2 \cdot 18(1 \cdot 07-4 \cdot 45)$ \\
\hline
\end{tabular}

CSA, Childhood sexual abuse; MZ, monozygotic; DZ, dizygotic; OR, odds ratio; CI, confidence interval. $n_{21}$, the number of doubly-discordant pairs in which the twin reporting CSA is also outcome-positive; $n_{12}$, the number of doubly-discordant pairs in which the twin reporting CSA is outcome-negative.

$\mathrm{OR}$ and $95 \% \mathrm{CI}$ are for combined $\mathrm{MZ}$ and $\mathrm{DZ}$ same-sex pairs.

Values are in bold face where OR is significant $(p<0 \cdot 05)$.

illicit drug (OR 2-18). Using data from discordant same-sex pairs to control for familial contributions to risk, persistent CSA-associated risk is seen for regular smoking, use of most classes of illicit drugs, and abuse/dependence of opioids, any illicit drug, and any non-cannabis illicit drug.

Separate discordant pair analyses (results not shown) performed to determine whether risk estimates differed by zygosity found significantly greater risk in DZ (OR $4 \cdot 20,95 \%$ CI $1 \cdot 58-11 \cdot 14)$ than in $\mathrm{MZ}$ pairs (OR $0 \cdot 75,95 \% \mathrm{CI}$ $0 \cdot 26-2 \cdot 16)$ only for opioid use. Similar analyses found significant gender differences only for cocaine use, with greater risk in male (OR 13.00, $95 \%$ CI 1.70-99.36) than in female (OR 1.25, $95 \%$ CI $0 \cdot 49-3 \cdot 17$ ) pairs.

Regression analyses found a significant contribution for a history of CSA, controlling for gender, to age at onset of regular nicotine and alcohol use (Table 4). Similar effects on the age at first use of illicit drugs were seen for all drug classes, but fell below significance for sedatives and cocaine; the largest effects were observed for cannabis and opioids. We examined whether a history of CSA was also associated with risk for early-onset cannabis use (Lynskey et al. 2003 ) and found significant risk (OR 2.93, 95\% CI 2.41-3.58), controlling for male gender (OR $2 \cdot 03,95 \%$ CI $1 \cdot 72-2 \cdot 40)$. These data confirm that CSA is associated with risk for earlier substance use onset.

An examination of the risks for the use of the other drug classes associated with both CSA and early-onset cannabis use, CSA alone, earlyonset cannabis use alone, and male gender found significantly greater risk for the use of all examined classes of illicit drugs associated with a history of both CSA and early-onset cannabis use than with either risk factor alone (Table 5). A similar examination of the risks for abuse/ dependence of the other illicit drugs classes observed greater risk associated with the presence of both CSA and early-onset cannabis use. Additional examinations revealed no significant interaction $(\mathrm{CSA} \times$ early-onset cannabis use) in any model (all $p$ values $>0 \cdot 10$ ). Thus, in those reporting both CSA and early-onset cannabis use, the risks associated with either factor alone combine in a near-additive fashion (i.e. the 
Table 4. Results of multivariate regression analyses examining the contribution of childhood sexual abuse (CSA) status and gender to the onset of substance use

\begin{tabular}{|c|c|c|c|}
\hline & \multirow[b]{2}{*}{ Intercept $(95 \% \mathrm{CI})$} & \multicolumn{2}{|c|}{ Regression coefficients $(95 \% \mathrm{CI})$} \\
\hline & & CSA status & Male \\
\hline \multicolumn{4}{|l|}{ Licit - regular use } \\
\hline Nicotine $(n=3063)$ & $16.77(16.60-16.93)$ & $-0.47(-0.79$ to $-0 \cdot 14)$ & $-0.28(-0.51$ to -0.05$)$ \\
\hline Alcohol $(n=5363)$ & $18 \cdot 62(18 \cdot 51-18 \cdot 73)$ & $-0.27(-0.52$ to -0.02$)$ & $-0.78(-0.93$ to -0.63$)$ \\
\hline \multicolumn{4}{|l|}{ Illicit - use } \\
\hline Cannabis $(n=3588)$ & $19 \cdot 43(19 \cdot 24-19 \cdot 62)$ & $-0.86(-1.19$ to -0.52$)$ & $-0.78(-1.02$ to -0.54$)$ \\
\hline Opioids $(n=386)$ & $22 \cdot 33(21 \cdot 60-23 \cdot 06)$ & $-1 \cdot 12(-2 \cdot 16$ to $-0 \cdot 09)$ & $0.09(-0.80$ to 0.97$)$ \\
\hline Sedatives $(n=523)$ & $21 \cdot 88(21 \cdot 27-22 \cdot 50)$ & $-0.42(-1.36$ to 0.51$)$ & $-0.86(-1.69$ to -0.03$)$ \\
\hline Stimulants $(n=1231)$ & $21 \cdot 37(21 \cdot 02-21 \cdot 73)$ & $-0.69(-1.25$ to $-0 \cdot 13)$ & $-0.02(-0.45$ to 0.41$)$ \\
\hline Cocaine $(n=381)$ & $23 \cdot 01(22 \cdot 35-23 \cdot 67)$ & $-0.47(-1 \cdot 41$ to $0 \cdot 47)$ & $0.64(-0.15$ to 1.43$)$ \\
\hline
\end{tabular}

CI, Confidence interval.

Values are in bold face where regression coefficient differs significantly from zero $(p<0 \cdot 05)$.

Table 5. The contributions ${ }^{\mathrm{a}}$ to the risk for use and abuse/dependence of illicit drugs from childhood sexual abuse (CSA), early-onset substance use, and both $(n=6050):(a)$ cannabis and $(b)$ regular smoking

\begin{tabular}{|c|c|c|c|c|}
\hline $\begin{array}{l}\text { Substance-related } \\
\text { outcome }\end{array}$ & $\begin{array}{l}\text { Both CSA and early-onset } \\
\text { cannabis use } \\
(n=185)\end{array}$ & $\begin{array}{l}\text { CSA only } \\
(n=559)\end{array}$ & $\begin{array}{c}\text { Early-onset } \\
\text { cannabis use only } \\
(n=649)\end{array}$ & $\begin{array}{c}\text { Male } \\
(n=2693)\end{array}$ \\
\hline \multicolumn{5}{|l|}{ Any use } \\
\hline Opioids & $7 \cdot 93(5 \cdot 46-11 \cdot 51)$ & $3 \cdot 02(2 \cdot 19-4 \cdot 16)$ & $3 \cdot 36(2 \cdot 56-4 \cdot 40)$ & $1.57(1.25-1.97)$ \\
\hline Sedatives & $9 \cdot 19(6 \cdot 53-12 \cdot 92)$ & $3 \cdot 13(2 \cdot 36-4 \cdot 14)$ & $4 \cdot 26(3 \cdot 35-5 \cdot 42)$ & $1 \cdot 06(0 \cdot 86-1 \cdot 30)$ \\
\hline Stimulants & $9 \cdot 93(7 \cdot 27-13.56)$ & $2 \cdot 23(1 \cdot 79-2 \cdot 79)$ & $4 \cdot 65(3 \cdot 88-5 \cdot 57)$ & $1.79(1.55-2 \cdot 08)$ \\
\hline \multicolumn{5}{|l|}{ Abuse/dependence } \\
\hline Opioids & $22.93(11 \cdot 91-44 \cdot 16)$ & $7 \cdot 11(3 \cdot 68-13 \cdot 76)$ & $4 \cdot 93(2 \cdot 57-9 \cdot 47)$ & $1.06(0 \cdot 63-1 \cdot 77)$ \\
\hline Sedatives & $32 \cdot 20(14 \cdot 15-73 \cdot 26)$ & $9 \cdot 80(4 \cdot 30-22 \cdot 34)$ & $7 \cdot 21(3 \cdot 18-16 \cdot 34)$ & $1 \cdot 66(0 \cdot 85-3 \cdot 21)$ \\
\hline Stimulants & $11 \cdot 11(7 \cdot 15-17 \cdot 26)$ & $2 \cdot 83(1 \cdot 85-4 \cdot 34)$ & $4 \cdot 80(3 \cdot 50-6 \cdot 60)$ & $1 \cdot 89(1.43-2 \cdot 51)$ \\
\hline Cocaine & $27 \cdot 15(10 \cdot 69-68 \cdot 97)$ & $2 \cdot 03(0 \cdot 43-9 \cdot 63)$ & $11 \cdot 11(5 \cdot 02-24 \cdot 58)$ & $2 \cdot 01(0 \cdot 98-4 \cdot 12)$ \\
\hline $\begin{array}{l}\text { Substance-related } \\
\text { outcome }\end{array}$ & $\begin{array}{l}\text { Both CSA and early } \\
\text { regular nicotine } \\
(n=230)\end{array}$ & $\begin{array}{l}\text { CSA only } \\
(n=508)\end{array}$ & $\begin{array}{l}\text { Early regular } \\
\text { nicotine use only } \\
\quad(n=911)\end{array}$ & $\begin{array}{c}\text { Male } \\
(n=2692)\end{array}$ \\
\hline \multicolumn{5}{|l|}{ Any use } \\
\hline Cannabis & $7 \cdot 97(5 \cdot 26-12 \cdot 08)$ & $2 \cdot 21(1 \cdot 80-2 \cdot 72)$ & $3 \cdot 28(2 \cdot 73-3 \cdot 93)$ & $2 \cdot 11(1 \cdot 97-2 \cdot 38)$ \\
\hline Opioids & $6 \cdot 71(4 \cdot 66-9 \cdot 65)$ & $3 \cdot 00(2 \cdot 15-4 \cdot 19)$ & $2 \cdot 43(1 \cdot 87-3 \cdot 17)$ & $1 \cdot 69(1 \cdot 35-2 \cdot 12)$ \\
\hline Sedatives & $7 \cdot 82(5 \cdot 71-10 \cdot 70)$ & $3 \cdot 04(2 \cdot 27-4 \cdot 06)$ & $2 \cdot 84(2 \cdot 26-3 \cdot 56)$ & $1 \cdot 15(0 \cdot 94-1 \cdot 40)$ \\
\hline Stimulants & $5 \cdot 67(4 \cdot 24-7 \cdot 58)$ & $2 \cdot 51(2 \cdot 01-3 \cdot 15)$ & $2 \cdot 69(2 \cdot 28-3 \cdot 17)$ & $1.93(1 \cdot 67-2 \cdot 23)$ \\
\hline Cocaine & $6 \cdot 06(4 \cdot 12-8 \cdot 92)$ & $2 \cdot 87(2 \cdot 03-4 \cdot 06)$ & $2 \cdot 35(1 \cdot 80-3 \cdot 07)$ & $2 \cdot 07(1 \cdot 63-2 \cdot 63)$ \\
\hline \multicolumn{5}{|l|}{ Abuse/dependence } \\
\hline Cannabis & $7 \cdot 80(5 \cdot 81-10 \cdot 48)$ & $2 \cdot 52(1 \cdot 97-3 \cdot 21)$ & $3 \cdot 40(2 \cdot 85-4 \cdot 05)$ & $2 \cdot 69(2 \cdot 30-3 \cdot 15)$ \\
\hline Opioids & $18 \cdot 90(9 \cdot 31-38 \cdot 37)$ & $9 \cdot 26(4 \cdot 73-18 \cdot 12)$ & $4 \cdot 56(2 \cdot 41-8 \cdot 63)$ & $1 \cdot 16(0 \cdot 70-1 \cdot 93)$ \\
\hline Sedatives & $25 \cdot 17(11 \cdot 24-56 \cdot 38)$ & $10 \cdot 49(4 \cdot 76-23 \cdot 11)$ & $4 \cdot 98(2 \cdot 20-11 \cdot 23)$ & $1 \cdot 86(0 \cdot 98-3 \cdot 54)$ \\
\hline Stimulants & $9 \cdot 75(6 \cdot 41-14 \cdot 84)$ & $2 \cdot 57(1.68-4 \cdot 20)$ & $3 \cdot 36(2 \cdot 47-4 \cdot 58)$ & $2.09(1.58-2 \cdot 76)$ \\
\hline Cocaine & $11 \cdot 27(4 \cdot 40-28 \cdot 91)$ & $2 \cdot 97(0 \cdot 93-9 \cdot 48)$ & $3 \cdot 31(1 \cdot 53-7 \cdot 15)$ & $2 \cdot 46(1 \cdot 23-4 \cdot 94)$ \\
\hline
\end{tabular}

a Analyses control for gender; odds ratios and $95 \%$ confidence intervals are reported.

Values are in bold face where the odds ratio is significant $(p<0 \cdot 05)$.

absence of any interaction reaching significance indicates that the risks associated with CSA and with early cannabis use combine in a manner that does not significantly differ from additive).
We conducted a similar set of analyses for early-onset regular smoking (before age 16), finding significant CSA-associated risk (OR $2 \cdot 38,95 \%$ CI 1.99-2.85), controlling for male 
gender (OR 1·39, $95 \%$ CI 1·20-1·61). We found a similar pattern of risks associated with either CSA or early-onset regular smoking alone or both in combination for outcomes that additionally included cannabis use and abuse/ dependence (Table 5). Further analyses again confirmed the absence of significant interactions. The risks associated with a history of CSA, and with early-onset substance use, for the use and abuse/dependence of illicit drugs appear to be largely additive.

\section{DISCUSSION}

Our analyses strongly support the association of CSA with risk for licit and illicit drug-related outcomes. We found that CSA is associated with risk for subsequently occurring drug use and, among users, for drug-related disorders. In analyses limited to CSA-discordant same-sex pairs in which the non-abused co-twin served as a control for the contribution of familial factors, we found similar CSA-associated risks for substance use. Similar examinations revealed significant risk only for opioid, any illicit drug, and any non-cannabis illicit drug abuse/ dependence. Although we found CSA to be a risk factor for earlier initiation of substance use, we observed that risks for illicit drug use and abuse/dependence associated with CSA combine in a largely additive manner with those from either early-onset cannabis use or early-onset regular smoking (i.e. no significant interaction).

Our findings are very consistent with prior studies that have examined the association of CSA with licit and illicit drug outcomes. Large, anonymous, school-based assessments of adolescents found CSA-associated risk for licit and illicit drug use, including the use of multiple classes of drugs (Harrison et al. 1997; Bensley et al. 1999). High CSA prevalence has been consistently reported in substance abuse treatment samples (Simpson \& Miller, 2002). Significant associations with alcohol and drug abuse and dependence have been observed in community samples of young adults (Mullen et al. 1993; Fergusson et al. 1996a) and in the National Comorbidity Survey sample (Molnar et al. 2001). Our results describe CSA-associated risks more comprehensively: (1) for the subsequent occurrence of both drug use and, among users, of drug-related disorders, (2) extending to both licit and illicit drug-related outcomes, and (3) of greatest magnitude for outcomes involving opioids and sedatives.

Our report is the first to examine drug use in CSA-discordant male and female same-sex twin pairs. Reporting on the largest CSA-discordant pair sample to date, we found that regular smoking and use of each class of drugs (the result for stimulants fell just below significance) are reported more frequently by twins with a history of CSA than their non-abused co-twins. Given the consistency of our discordant pair and survival analysis results, we conclude that CSA-associated risks for regular smoking and illicit drug use are only mildly attenuated with co-twin control for the contributions of familial risk factors.

We previously reported significant CSAassociated risks for nicotine dependence and alcohol dependence in discordant pair analyses of this sample's data (Nelson et al. 2002). In similar analyses, Kendler et al. (2000) observed some significant risk for (any illicit) drug dependence and more consistent risk for alcohol dependence. As noted, their analyses had limited power. For most classes of illicit drugs, we probably faced similar limitations as best exemplified by the non-statistically significant OR of 4.5 for sedative abuse/dependence. The significant risks that we found for abuse/ dependence combined across all drug classes, and for non-cannabis illicit drugs, suggest limited power for individual drug classes and are inconsistent with findings due to differing drug preferences between pair members.

Our finding of earlier drug use associated with CSA is consistent with prior reports. Earlier initiation of licit and illicit drug use has been reported for adolescents with a history of CSA assessed in either school (Harrison et al. 1997; Bensley et al. 1999) or treatment (Harrison et al. 1989) settings. Earlier injection drug use by those with a history of CSA has been reported in human immunodeficiency virus (HIV)-seropositive men (Holmes, 1997) and male and female injection drug users (Ompad et al. 2005). Our results examining the combined effects of CSA and early-onset regular smoking or cannabis use suggest that individuals with a history of CSA who develop earlyonset substance use are at very high risk for 
progression to other illicit drug use and abuse/ dependence.

Additional study is needed to determine whether this progression can be prevented by identifying these individuals and intervening. Given that CSA-associated risks are likely to arise from a variety of sources, determining the best routes for intervention could prove challenging. Education could increase risk awareness, facilitating delayed substance use and progression. Community efforts could provide safe, supportive and substance-free alternatives to the dangerous, harsh or substance-laden home and extra-familial environments in which victimization often occurs. Treatment aimed at limiting psychiatric sequelae and attempted selfmedication could diminish risk associated with emergent affective and anxiety disorders. Psychotherapy, in conjunction with the above, could aid formation of healthy relationships with contemporary peers, thereby slowing transitions to adult roles.

It is becoming increasingly clear that attempts at parsing risk to genetic and environmental components underestimate the complex biological underpinnings. Persistent alterations in stress responsivity have been observed in women with a history of CSA (Heim et al. 2000, 2001) and in adult rats repetitively separated as pups from their dams (Caldji et al. 1998, 2000). The latter also display long-lasting changes in morphine sensitization, tolerance and withdrawal (Kalinichev et al. 2001, 2002) and have reduced levels of both gamma-aminobutyric acid type $A\left(\mathrm{GABA}_{\mathrm{A}}\right)$ and central benzodiazepine receptors in regions implicated in hypothalamic-pituitary-adrenal (HPA) axis regulation (Caldji et al. 1998, 2000). Thus, exposure to severe early trauma may lead to persistent alterations in gene expression. Furthermore, reports (Caspi et al. 2002, 2003) of significant $\mathrm{G} \times \mathrm{E}$ interactions involving childhood abuse and functional genetic polymorphisms for related outcomes (i.e. depression and antisocial behaviour) have had replications published (Eley et al. 2004; Foley et al. 2004; Kaufman et al. 2004; Kendler et al. 2005). Therefore, risk associated with a severe stressor is likely to alter gene expression, which, in genetically predisposed individuals, may be associated with risk for more distal sequelae. Similar investigations targeting risk for SUDs are clearly warranted and should incorporate recently reported additional layers of complexity (i.e. mitigation of risk with social support and gene-gene interaction) (e.g. Kaufman et al. 2006).

A variety of limitations must be considered when interpreting our results. As the twins were initially recruited as children, their parents may have been less likely to volunteer twins with a history of CSA. However, because more severe CSA is associated with greater risk for substance use and dependence (Mullen et al. 1993; Fergusson et al. 1996a; Kendler et al. 2000), any effect would probably have reduced associations. The similarity of our prevalence rates to those obtained in community samples (Fergusson et al. 1996b; Fleming, 1997; Holmes \& Slap, 1998) suggests that our sample is reasonably representative. CSA is a complex construct; our use of a single binary variable is an oversimplification that may have led to underestimated CSA-associated risks. We chose to do so both to simplify interpretation of the discordant pair comparisons and because of limitations in our CSA assessment. Physical abuse (PA) is often present with CSA in families (Fleming et al. 1997; Dong et al. 2003; Walsh et al. 2003) and has also been associated with risk for drug-related outcomes (Simpson \& Miller, 2002). We narrowed our focus to CSA largely because our PA assessment was much more limited. Additional analyses that incorporated PA with CSA into a more general construct, childhood abuse, yielded very similar results throughout (available on request), suggesting that the risks we observed probably extend beyond CSA to include PA. Our use of retrospective self-report data, while another potentially important source of bias, is largely unavoidable. One examination (Fergusson et al. 2000) of the stability of CSA reports found no relationship between variations in reports and psychiatric status before, during or after the reported abuse.

Despite the considerable size of our sample, power limitations impacted the significance of our discordant pair findings. We opted to combine data from pairs of different zygosity and sex to avoid further reductions in power. This makes interpretation of our findings less straightforward than analyses limited to MZ pairs (which completely control for genetic and 
family environmental risk factors). However, it is important to recognize that even analyses limited to discordant MZ pairs cannot exclude the possibility of findings arising from a proximal latent factor (e.g. a difference in foetal environment) associated with risk for both variables in the model. Conversely, because the significant interactions involving covariates arose from analyses that further subdivided relatively small numbers of doubly-discordant pairs, we believe that they require replication. However, the significant interaction involving gender could reflect differential use patterns because, among the illicit drugs, the greatest risk in males was seen for cocaine. Similarly, an interaction involving zygosity could occur if a heritable trait (e.g. conduct disorder) is associated with increased risk for CSA and for opioid use. Our use of age 17 as the cut-off for CSA may have led to a more heterogeneous construct that included both early childhood molestation and adolescent victimization (e.g. date rape), to which heritable risks could be contributing. As participants remain at risk for drug-related outcomes, risks due to an earlier onset in CSA-positive twins may decrease over time.

In summary, our results strongly support the association between CSA and subsequently occurring licit and illicit drug outcomes. Our results confirm an earlier onset of regular licit and illicit drug use with CSA while finding no significant interaction between risks associated with CSA and with early-onset substance use. Further studies are needed to explore potential biological underpinnings (e.g. $\mathrm{G} \times \mathrm{E}$ interactions) and to determine whether risks for drug-related outcomes can be mitigated by identifying 'at-risk' individuals early and intervening.

\section{ACKNOWLEDGEMENTS}

This work was supported by NIH Grants AA07728, AA10249, AA11998(ACH), AA13446 and DA17305 (ECN), and Australian National Health and Medical Research Council Grants 941177 and 981351 (NGM).

\section{DECLARATION OF INTEREST}

None.

\section{REFERENCES}

APA (1994). Diagnostic and Statistical Manual of Mental Disorders (4th edn). American Psychiatric Association: Washington, DC.

Australian Institute of Health and Welfare (1999). 1998 National Drug Strategy Household Survey: First Results. Australian Institute of Health and Welfare: Canberra, Australia.

Bartholomew, N. G., Rowan-Szal, G. A., Chatham, L. R., Nucatola, D. C. \& Simpson, D. D. (2002). Sexual abuse among women entering methadone treatment. Journal of Psychoactive Drugs 34, 347-354.

Bensley, L. S., Spieker, S. J., Van Eenwyk, J. \& Schoder, J. (1999). Self-reported abuse history and adolescent problem behaviors. II. Alcohol and drug use. Journal of Adolescent Health 24, 173-180.

Bucholz, K. K., Cadoret, R., Cloninger, C. R., Dinwiddie, S. H., Hesselbrock, V. M., Nurnberger, J. I., Jr., Reich, T., Schmidt, I. \& Schuckit, M. A. (1994). A new, semi-structured psychiatric interview for use in genetic linkage studies: a report on the reliability of the SSAGA. Journal of Studies on Alcohol 55, 149-158.

Caldji, C., Francis, D., Sharma, S., Plotsky, P. M. \& Meaney, M. J. (2000). The effects of early rearing environment on the development of GABA-A and central benzodiazepine receptor levels and novelty-induced fearfulness in the rat. Neuropsychopharmacology 22, 219-229.

Caldji, C., Tannenbaum, B., Sharma, S., Francis, D., Plotsky, P. M. \& Meaney, M. J. (1998). Maternal care during infancy regulates the development of neural systems mediating the expression of fearfulness in the rat. Proceedings of the National Academy of Sciences USA 95, 5335-5340.

Caspi, A., McClay, J., Moffitt, T. E., Mill, J., Martin, J., Craig, I. W., Taylor, A. \& Poulton, R. (2002). Role of genotype in the cycle of violence in maltreated children. Science 297, 851-854.

Caspi, A., Sugden, K., Moffitt, T. E., Taylor, A., Craig, I. W., Harrington, H., McClay, J., Mill, J., Martin, J., Braithwaite, A. \& Poulton, R. (2003). Influence of life stress on depression: moderation by a polymorphism in the 5-HTT gene. Science 301, 386-389.

Clark, D. B., Lesnick, L. \& Hegedus, A. M. (1997). Traumas and other adverse life events in adolescents with alcohol abuse and dependence. Journal of the American Academy of Child and Adolescent Psychiatry 36, 1744-1751.

Dong, M., Anda, R. F., Dube, S. R., Giles, W. H. \& Felitti, V. J. (2003). The relationship of exposure to childhood sexual abuse to other forms of abuse, neglect and household dysfunction during childhood. Child Abuse and Neglect 27, 625-639.

Eley, T. C., Sugden, K., Corsico, A., Gregory, A. M., Sham, P., McGuffin, P., Plomin, R. \& Craig, I. W. (2004). Gene-environment interaction analysis of serotonin system markers with adolescent depression. Molecular Psychiatry 9, 908-915.

Fergusson, D. M., Horwood, L. J. \& Lynskey, M. T. (1996a). Childhood sexual abuse and psychiatric disorder in young adulthood: II. Psychiatric outcomes of childhood sexual abuse. Journal of the American Academy of Child and Adolescent Psychiatry 35, $1365-1374$.

Fergusson, D. M., Horwood, L. J. \& Woodward, L. J. (2000). The stability of child abuse reports: a longitudinal study of the reporting behaviour of young adults. Psychological Medicine 30, 529-544.

Fergusson, D. M., Lynskey, M. T. \& Horwood, L. J. (1996b) Childhood sexual abuse and psychiatric disorder in young adulthood: I. Prevalence of sexual abuse and factors associated with sexual abuse. Journal of the American Academy of Child and Adolescent Psychiatry 35, 1355-1364.

Fleming, J. M. (1997). Prevalence of childhood sexual abuse in a community sample of Australian women. Medical Journal of Australia 166, 65-68.

Fleming, J., Mullen, P. \& Bammer, G. (1997). A study of potential risk factors for sexual abuse in childhood. Child Abuse and Neglect 21, 49-58.

Foley, D. L., Eaves, L. J., Wormley, B., Silberg, J. L., Maes, H. H., Kuhn, J. \& Riley, B. (2004). Childhood adversity, monoamine 
oxidase A genotype, and risk for conduct disorder. Archives of General Psychiatry 61, 738-744.

Harrison, P. A., Fulkerson, J. A. \& Beebe, T. J. (1997). Multiple substance use among adolescent physical and sexual abuse victims. Child Abuse and Neglect 21, 529-539.

Harrison, P. A., Hoffmann, N. G. \& Edwall, G. E. (1989). Differential drug use patterns among sexually abused adolescent girls in treatment of chemical dependency. International Journal of Addictions 24, 499-514.

Heath, A. C., Bucholz, K. K., Madden, P. A. F., Dinwiddie, S. H., Slutske, W. S., Bierut, L. J., Statham, D. B., Dunne, M. P., Whitfield, J. B. \& Martin, N. G. (1997). Genetic and environmental contributions to alcohol dependence risk in a national twin sample: consistency of findings in women and men. Psychological Medicine 27, 1381-1396.

Heath, A. C., Howells, W., Kirk, K. M., Madden, P. A. F., Bucholz, K. K., Nelson, E. C., Slutske, W. S., Statham, D. J. \& Martin, N. G. (2001). Predictors of non-response to a questionnaire survey of a volunteer twin panel: findings from the Australian 1989 twin cohort. Twin Research 4, 73-80.

Heim, C., Newport, D. J., Bonsall, R., Miller, A. H. \& Nemeroff, C. B. (2001). Altered pituitary-adrenal axis responses to provocative challenge tests in adult survivors of childhood abuse. American Journal of Psychiatry 158, 575-581.

Heim, C., Newport, D. J., Heit, S., Graham, Y. P., Wilcox, M., Bonsall, R., Miller, A. H. \& Nemeroff, C. B. (2000). Pituitary-adrenal and autonomic responses to stress in women after sexual and physical abuse in childhood. Journal of the American Medicine Association 284, 592-597.

Holmes, W. C. (1997). Association between a history of childhood sexual abuse and subsequent, adolescent psychoactive substance use disorder in a sample of HIV seropositive men. Journal of Adolescent Health 20, 414-419.

Holmes, W. C. \& Slap, G. B. (1998). Sexual abuse of boys: definition, prevalence, correlates, sequelae, and management. Journal of the American Medicine Association 280, 1855-1862.

Kalinichev, M., Easterling, K. W. \& Holtzman, S. G. (2001). Early neonatal experience of Long-Evans rats results in long-lasting changes in morphine tolerance and dependence. Psychopharmacology 157, 305-312.

Kalinichev, M., Easterling, K. W. \& Holtzman, S. G. (2002). Early neonatal experience of Long-Evans rats results in long-lasting changes in reactivity to a novel environment and morphineinduced sensitization and tolerance. Neuropsychopharmacology $\mathbf{2 7}$, $518-533$.

Kaufman, J., Yang, B. Z., Douglas-Palumberi, H., Grasso, D., Lipschitz, D., Houshyar, S., Krystal, J. H. \& Gelernter, J. (2006). Brain-derived neurotrophic factor-5-HTTLPR gene interactions and environmental modifiers of depression in children. Biological Psychiatry 59, 673-680.

Kaufman, J., Yang, B. Z., Douglas-Palumberi, H., Houshyar, S. Lipschitz, D., Krystal, J. H. \& Gelernter, J. (2004). Social supports and serotonin transporter gene moderate depression in maltreated children. Proceedings of the National Academy of Sciences USA 101, 17316-17321.

Kendler, K. S., Bulik, C. M., Silberg, J., Hettema, J. M., Myers, J. \& Prescott, C. A. (2000). Childhood sexual abuse and adult psychiatric and substance use disorders in women: an epidemiological and cotwin control analysis. Archives of General Psychiatry 57, 953-959.

Kendler, K. S., Jacobson, K. C., Prescott, C. A. \& Neale, M. C (2003). Specificity of genetic and environmental risk factors for use and abuse/dependence of cannabis, cocaine, hallucinogens, sedatives, stimulants, and opiates in male twins. American Journal of Psychiatry 160, 687-695.

Kendler, K. S., Kuhn, J. W., Vittum, J., Prescott, C. A. \& Riley, B. (2005). The interaction of stressful life events and a serotonin transporter polymorphism in the prediction of episodes of major depression: a replication. Archives of General Psychiatry 62, 529-535.

Knopik, V.S., Heath, A. C., Madden, P. A. F., Bucholz, K. K., Slutske, W. S., Nelson, E. C., Statham, D., Whitfield, J. B. \& Martin, N. G. (2004). Genetic effects on alcohol dependence risk: re-evaluating the importance of psychiatric and other heritable risk factors. Psychological Medicine 34, 1519-1530.

Lynskey, M. T., Heath, A. C., Bucholz, K. K., Slutske, W. S., Madden, P. A. F., Nelson, E. C., Statham, D. B. \& Martin, N. G. (2003). Escalation of drug use in early-onset cannabis users vs cotwin controls. Journal of the American Medicine Association 289 , $427-433$.

Lynskey, M. T., Heath, A. C., Nelson, E. C., Bucholz, K. K., Madden, P. A. F., Slutske, W. S., Statham, D. J. \& Martin, N. G. (2002) Genetic and environmental contributions to cannabis dependence in a national young adult twin sample. Psychological Medicine 32 195-207.

Molnar, B. E., Buka, S. L. \& Kessler, R. C. (2001). Child sexual abuse and subsequent psychopathology: results from the National Comorbidity Survey. American Journal of Public Health 91, 753-760.

Mullen, P. E., Martin, J. L., Anderson, J. C., Romans, S. E. \& Herbison, G. P. (1993). Childhood sexual abuse and mental health in adult life. British Journal of Psychiatry 163, 721-732.

Nelson, E. C., Heath, A. C., Madden, P. A. F., Cooper, M. L., Dinwiddie, S. H., Bucholz, K. K., Glowinski, A. L., McLaughlin, T. Dunne, M. P., Statham, D. J. \& Martin, N. G. (2002). Association between self-reported childhood sexual abuse and adverse psychosocial outcomes: results from a twin study. Archives of General Psychiatry 59, 139-145.

Ompad, D. C., Ikeda, R. M., Shah, N., Fuller, C. M., Bailey, S., Morse, E., Kerndt, P., Maslow, C., Wu, Y., Viahov, D., Garfein, R. \& Strathdee, S. A. (2005). Childhood sexual abuse and age at initiation of injection drug use. American Journal of Public Health 95, 703-709.

SAS Institute (2000). AS/STAT: Users Guide, Version 8.00. SAS Institute, Inc.: Cary, NC.

Simpson, T. L. \& Miller, W. R. (2002). Concomitance between childhood sexual and physical abuse and substance use problems A review. Clinical Psychology Review 22, 27-77.

Stata Corporation (1999). Stata Statistical Software: Release 6.0. Stata Corporation: College Station, TX.

Tsuang, M. T. \& Lyons, M. (1998). Co-occurrence of abuse of different drugs in men: the role of drug-specific and shared vulnerabilities. Archives of General Psychiatry 55, 967-972.

Walsh, C., MacMillan, H. L. \& Jamieson, E. (2003). The relationship between parental substance abuse and child maltreatment: findings from the Ontario Health Supplement. Child Abuse and Neglect 27, 1409-1425. 